\title{
Defining Vision: What Homology Thinking Contributes
}

\author{
Mohan Matthen \\ Institute for the History and Philosophy of Science and Technology, \\ University of Toronto, \\ 91 Charles St. W., \\ Toronto ON M5S1K7, Canada \\ Email: mohan.matthen@utoronto.ca
}

\begin{abstract}
The specialization of visual function within biologic al function is reason for introducing "homology thinking" into explanations of the visual system. It is argued that such specialization arises by organisms evolving by differentiation from their predecessors. Thus, it is essentia lly historic al, and visual function should be regarded as a lineage property. The colour vision of birds and mamma ls do not function the same way as one a nother, on this account, because each is an adaptation to special needs of the visual functions of predecessors - very different kind s of predecessors in each case. Thus, history und enlies function. We also see how homology thinking figures in the hierarchical classific ation of visual systems, and how it supports the explanation of visual function by functional role ana lysis.
\end{abstract}




\section{Defining Vision: What Homology Thinking Contributes ${ }^{1}$}

\section{Introduction: Homology and Classification}

Biological taxonomy consists of dividing organisms, their parts, their subsystems, and their a ctivities into kinds for explanatory purposes. A taxonomy of organisms yields a division into species, genera, and other taxa in what used to be known as the Linnaean hierarchy. A taxonomy of organs results in concepts such as heart, liver, brain, vertebra, etc. across Linnaean taxa. A subsystems-taxonomy delivers kinds such as visual system, rationality, emotion, etc., similarly across taxa. Even behaviour can be taxonomized, yielding categories such as: dominance relationship, courtship ritual, smile (see Ereshefsky, this issue).

It is often unclear how to demarcate such kinds. We think, with some plausibility, that we know what a human smile is (though recall how disappointed new parents can be, when they leam that their newbom's angelic expression is not a smile but an indication of gastric events). Similarly, it is reasonably obvious to doctors what a human liver or heart is, and how to identify the same organ in a dog. But it is not so obvious to the inexpenienced when a dog is smiling, whether it is displaying submission or aggression, and which bones in its foreleg correspond to primate fingers. By the same token, human physiology does not tell us how to go about determining whether a lobster possesses a heart (Tjønneland et al. 1987). And it is was, until recently, a matter of theoretical dispute whether a pigeon or liza rd possesses anything that ought to be classed with the mammalian primary visual cortex. Identifying a feature or item within a taxon is one kind of problem; identifying it across taxa is often a nother.

In these cases, what is in question is the comparative prionity of different principles of classification. The biologic al systematist attempts to capture deep commonalities - characteristics that best account for clusters of other characteristics. Thus, having a heart might not only coincide with, but account for, having lungs, circulatory system, and kidneys: the former may in some sense

1 Many thanks to my fellow symposiasts for incisive disc ussion and many new ideas: Ingo Brigandt, Marc Ereshefsky, Paul Griffiths, and Alan Love. Special thanks to Paul and Ingo for written comments. 
account for the rest, but not vice versa. (The example is for illustrative purposes only - it does not pretend to biological plausibility.) Often, however, classes constructed in this way will cross-cut: one characteristic will be the font of one set of properties, a nother characteristic of another set. Thus, something might be assigned to a class $C$ in order to understand why it is $F$, and to class $C^{\prime}$ in order to understand why it is $G$, where $C$ and $C^{\prime}$ do not completely overlap. The question as far as the classes designated vertebra, heart, smile, eye are concemed is: What commonalities do they capture? What is their principle of classification?

Homology thinking - this is Marc Ereshefsky's (this issue) suggestive term comes into play when things are grouped together only when they share a common evolutionary origin." As Ereshefsky defines it: "Homology thinking a na lyzes traits in tems of their common ancestry." Thus,

A homology-class is a class $C$ such that:

a) C contains a n original item, $A$, and

b) if $x$ is a member of $C$ and $x \neq A$, then $x$ evolved from $A .^{3}$

Homology thinking contrasts with phenetic thinking, which constructs classes tra its by similarity, and analogy thinking, which constructs them by commonality of use-function (see Love, this issue, for "use-function") - both with no consideration of origin. Smiles constitute a homology class if it is necessary that anything counted as a smile must trace back to a common evolutionary origin.

2 I am being deliberately vague when I speak of "things" being grouped together by common ancestry. These "things" can be traits, bone structures, behaviours, etc. See Matthen (2000) for a historical account, and Brigandt (this issue), Griffiths (this issue) and Love (this issue) for orig inal disc ussion.

3 I take "evolved from" to be an incompletely explic ated historical notion that a waits further a nalysis. See, however, Brigandt (this issue) on 'evolva bility' and Griffiths (this issue) for the importance of genetic and developmental processes in operational definitions of homology. I will rest content with treating homology as something of a black box, since my interest is in an application of homology thinking, not its explic ation. I do not speak, for example, about serial homology, though I assume that the definition given can be fleshed out in such a way as to include it. 
The topic to be investigated in this paper is how homology-classes figure in expla nations of the visual system.

Linnaeus believed that species and genera should be defined in terms of shared features; this was phenetic ist thinking. Nowadays, it is generally thought that species and genera should instead be demarcated in terms of common origins (Sober 1988; Ereshefsky 2001). This is homology thinking. In cladism, the apotheosis of homology thinking, quondam Linnaean taxa become monophyletic groups - i.e., they contain all and only the descendants of a common ancestor. (Monophyletic groups are defined by promoting the 'ifthen' in clause (b) above to an 'if and only if'.) In some other classificatory schemes, taxa can be paraphyletic groups - i.e., they may include only those descendants of a common ancestor that satiffy some further criterion, but not other descendants of that ancestor. Both sorts of scheme mark a move to homology thinking a bout the classes that constitute the Linnaean hierarchy. The shift to homology thinking occurred it was thought that homology thinking better captures certain fundamental characteristics of biological taxa - that they cluster in morphological space, that they are polymorphic, that species continue under evolution - better than the altematives.

Certa in important features of homology thinking should be noted.

1. Homology thinking is not a priori.

It is neither a conventional choice regarding teminology nor amived at by conceptual analysis of scientific vocabulary. Rather, homology thinking is adopted in a particular domain because it is thought to be the best theoretical approach to the explanation of a certain set of features in that domain, given empincal facts about it. For example, it is adopted as a way of identifying a dog's physical gesture as one of submission, or a structure in a bird's Wulst as its primary visual cortex, because grouping these things together with others of common origin explains their morphology, system connectivity, functional role, and adaptive function better than altemative taxonomical approaches. As we shall see, other explanatory needs might indicate other kinds of taxonomical thinking.

Moreover, 
2. Homology judgements are made on the basis of objective structural, biomechanical, and developmental parallels that can be observed independently of the facts being explained (cf. Griffiths, this issue), but ...

3. ... Homology thinking accommodates variation in the biological doma in without resort to subjec tive or a rbitrary distinc tions. ${ }^{4}$

In this paper, I a m interested in homology thinking about the visual system. (See Griffiths 1994, 1997, 2007 and Matthen 1998, 2000 for earlier philosophical investigations of homological thinking in the cognitive domain.) I shall argue that common origins a re expla na tory with regard both to what visual systems do - their function - and to how they are organized. As we shall see, homology thinking casts light on the functional orga nization of the visual system, and shows how visual functions emerge from the adaptation and re-adaptation of the same parts to different roles in a larger system.

\section{Specialized Visual Function}

The occasion for homology thinking about the visual system is the specia lization of visual function in various groups of a nimals. In this section, I expla in what this specialization is, and in the next, I suggest how homology thinking might be useful in explaining it. My aim here is to show how homology thinking is much more intertwined with thinking about function than philosophers and biologists generally a llow. Part of the point that I want to make is this: Homology thinking is essential for understanding proper (or selected effect) function.

${ }^{4}$ Karen Neander (2002) rightly insists that any adequate taxonomy should be able to accommodate variation and loss of functionality - organs of different size, genetic ally defective and diseased organs, and so on. She argues that only definitions in terms of teleological functions can accommodate such variation adequately (since something can possess a function but not perform it). She is wrong about this: the historically based definition of homology-class accommodates variation, but does not mention teleological functions. In fact, Neander herself implicitly appeals to historical origins. for it is only by identifying relations of evolutionary descent that natura lized teleology gets a grip on variation. Thus, I would claim that notions such as that of a "reproduc tively established family" (cf. Millikan 1984) implic itly appeal to homology-classes (see Griffiths, this issue). Neander and other proponents of historical approaches to "properfunction" are in the same boat. 
The traditional view in philosophy is that visual sensation consists of something like a point-to-point translation (or transduction) of the retinal image(s) (perhaps with some transfomations of retinotopic spatial considerations). From this translation, it is a rgued, we extract - post-perceptually as it were - a map or record of the extemal world. I shall call this the Pictorial View. From the Pictorial View, it would follow that since birds share lenses, retinas, and many retinal transducers (rod and cone cells) with primates, these two groups must be quite compatible in terms of visual sensation. There is little room for specialization of visual function on this view: hence no need to divide visual systems up into types or kinds. There would thus be no occasion for homology thinking about vision.

I have argued elsewhere (Matthen 2005) that the Pictorial View of visual sensation is wrong-headed. From the retina on up to the occipital lobes of the brain, the visual system actively extracts data conceming the extemal world from cues and indic ations present in the retinal image and in other sources (for example, proprioception and audition). The extracted data feeds into two kinds of further process. First, it feeds into automatic processes of recordkeeping - conditioning, a process by which one environmental feature is associated with another, priming, a process by which incomplete data are completed by analogy with things encountered in the past, and habituation, a process by which attention is diverted away from relatively invariant features of the environment. Second, it feeds into epistemic processes that the organism controls - for instance, belief-formation. The visual system may determine that a particular object is square or that it is red, and the organism may reason from this to the nature of the object, or use other considerations to a mive at the opposite belief.

Visual sensation is the record of data extracted in this way - it is an intemal signal by which the perceiver comes to be able to make use of extracted visual data for epistemic purposes. When you see something as blue or as round, i.e., when the visual system presents you with a blue-quale or a round-quale, it is signalling that this thing should, for the above-mentioned epistemic purposes, be treated the same way as other things that appear the same way. (You, are, of course, entitled to weigh other bits of evidence in deciding whether to do as the visual system signals you should.) For example, the thing is to be treated in 
similar ways as far as inferences you would draw with reference to other blue things or other round things.

Evidently, this second perspective on sensation - which I entitle the Sensory Classification Perspective - both indicates and accommodates more inter-species differences than the Pictorial View. There is a great deal of data that could be extracted from retinal images, given the right kinds of dataprocessing protocols. Not all of it is useful to every kind of a nimal. So you might think that one visual system might have evolved to extract visual data that best suits the needs of the type of organism it serves, while another might have evolved to extract different data from the same (or a slightly different) retinal image.

The specialized visual function suggested by the Sensory Classification Perspective is very much the stuff of comparative studies of vision. Here is a representative complaint from J uan Delius:

There is a propensity among researchers to ignore the fact that the visual functions of species, breeds, and even individuals may differ as a consequence of their differing phylogenetic and ontogenetic histories. (Delius et al. 2000: 6)

Delius and co-authors complain about the "mistaken equation of pigeon and human vision". They are suggesting both that pigeon vision is not the same as human vision, and that it does not have the same function. In the next few paragraphs, I provide a few illustrations of what they mean.

First, consider colour vision. For diumal a nima ls, it is a n asset; for noc tumal ones, it is a lia bility (since colour receptors a re relatively insensitive to light). Birds started out as diumal animals. Thus, many birds have good colour vision. Mammals, on the other hand, were initially noctumal, and most have poor colour vision at best. Partly, this is a matter of receptors: good colour vision requires three or four cone-cell types; most birds have this many, most mammals have fewer. It is also a matter of data-extraction: the outputs of cone-cells have to undergo an elaborate processing before they yield the kinds of colour-data that a re useful to an organism. Birds have had colour vision for a long time, and have evolved to extract data that is particularly relevant in their aerial environments. Among mammals, good colour vision re-emerged in old-world monkeys, presumably in response to a specific challenge that they faced in their jungle environments. Primate colour vision systems do different things with 
colour information than birds do. They see differently in colour. (More about this later.)

Other examples of species variability abound. Avian visual systems use the concentration of ultraviolet light in different parts of the sky to compute directions relative to the sun. Honeybee visual systems achieve the same result by detecting polarization. Thus, birds and honeybees extract data about direction from information in their retinal images. They see direction, if you like, and use the extracted data forpath-finding purposes. The human visual system delivers no data about direction. Again, this has something to do with receptors: humans have no polarization or ultra-violet detectors. At the same time, receptors do not tell the whole story. Information about direction has to be extracted from the outputs of polanization and ultra-violet receptors. Donning polarized sunglasses will put polarization information on the human retina - in a form to which our visual receptors a re sensitive, as witness the way the world looks through pola rizers. But it will not enable the human visual system to extract data about directions from the image.

A more recherché example is picture recognition. Humans look at photographs and extract information not only about the photograph itself - i.e., about the coloured marks on paper - but also about the objects they see in the photograph. Pigeons have a much more limited capacity to do this (Delius et. al. 2000). Now why should this be? Photographs project in much the same way to pigeon retinas as they do to human retinas; thus if the traditional view is correct, the propensity of humans to see objects in pictures should be pretty much the same as in pigeons. The Sensory Classification Perspective provides an answer. If pigeons fail visually to capture detailed information about things from photographs of these things, it is not because the retinal images thrown by photographs are so very different from those thrown by their subjects. Rather, it is because pigeon visual systems do not (for whatever reason) extract the relevant data from the retinal image of a photograph. That humans leam about places and things from photographs is not because the retinal image is so apt for this: if it were, pigeons should be able to do the same. The human ability is explained not by the nature of human eyes, but the nature of human visual data-processing.

Similar things can be said about distance. Humans walk; pigeons fly. Human visual systems are bad at delivering distance-data about things in the 
sky - if there is no land-bound path between a human perceiver and a target, humans cannot tell simply by looking how far away the target is. The human

visual system employs gradients of visible texture and perspectival effects to estimate distance (greater than a certain amount). These are absent in a erial environments. Thus, objects in the sky look indeterminate in size and distance. By contrast it is immediately evident how long it would take to a not-too-faraway target on the land - not that one is always correct in such an estimate. Pigeons and other birds a re not simila rly handicapped; their distance estimates do not require them to be able to see a portion of the surface of the Earth connecting themselves to the target. They use optic flow and other temporally extended methods to estimate distance to target.

Finally, consider the visually based recognition of organisms of the same species. Humans employ a bra in area known as the Fusiform Face Area for this purpose; bats use the acoustic signature of sounds emitted for purpose of echolocation; birds, presumably, have quite a different mechanism. Humans are adept at reading the emotions of other humans in facial expression etc., presumably birdscannot read human emotion.

The list goes on and on.

\section{Specialization and Phylogeny}

How shall we explain the specialization of visual function reviewed in the previous section? Is homology thinking relevant?

Very roughly summarized, here a re some details conceming the orig ins of avian and mammalian visual systems:

4. Birds and mammals both have visual systems that descend from a reptilian ancestor. This ancestor belonged to a diumal, terrestrial class of animals that out-competed these descendants under these conditions.

5. Birds retain the diumal habits of reptiles, but moved to an aerial environment. Their visual system is adapted to this environment in many ways, some of which were discussed above. 
6. Mammals escaped reptilian competition by adopting a noctumal lifestyle. They lost diumal vision. Later, however, when the reptiles underwent major extinctions and left the earth freer for others, they regained it. At this point, their visual systems re-adapted to diumal ta sks by a modific a tion of cortic al systems.

7. Thus, certa in "visual functions" of each of these groups originated after their lineages had separated from each other.

Homology thinking detects hiera rc hic a lly nested kind s here. First, there is a broad class of visual systems that are united by the reptilian point of origin. This group excludes other visual systems with even more ancient origins, which we shall mention later - those of amphibians, invertebrates, etc. Certain commona lities of function between avian and mammalian visual systems will be attributed to the broad class; certain others to convergence in a diumal environment. Second, there are na rrow subclasses of visual systems that perta in to the histories outlined in (5) and (6) above. Visual systems within the subclasses have common origins, but the subtypes themselves have different origins from one a nother. These points of origin are more recent than that of the broader kind. There are visual functions specific to each of these subtypes. Homology thinking diagnoses these commonalities and divergences of visual function to these origins.

Now, we need to supplement the above phylogeny if it is to be made to support homology thinking about visual systems. For from the fact that the visual systems of birds and mammals have both different functions and separate origins, it does not follow that their different functions can be attributed to the separate origins (i.e., that, as Delius et. al. say, "individuals may differ as a consequence of their differing phylogenetic and ontogenetic histories"). For it might be that the differences of function should be attributed not to history but to divergent ecological pressures. After all, mammals and birds engage in different kinds of visually guided activity - walking vs. flying, hunting vs. eluding predators - and hence, one might say, their visual systems have to function differently to subserve these diverse activities. Such an approach considers variable function in terms of variable ecology and adaptation, but not in tems of different origins. 
I shall start to motivate the case for homology thinking by describing two ways of thinking about how organisms adapt to their environments.

Conception 1 (Adaptationism) Suppose that adaptation consisted simply in solving certain broad problems posed by the environment. (For a critique, see Lewontin 1980.) Origins would then be irrelevant to the classification of visual systems. Classification would be by kinds of environment, not by history. Homology thinking would have no place in this case. Specialized cognitive systems would fall into classes that closely parallel the kinds of environment they inhabit: history would only tell us how and when they got to that kind of environment. This approach is adaptationist in the following sense. It takes function to be completely determined by environment, and environment to be given independently of organisms and history. And it assumes that evolution works by making the organism fit for the environment.

Conception 2 (Specialization as Differentiation) Here is a contrasting approach to adaptation. A successful species $S$ puts pressure on environmental resources because it grows in numbers. If a sub-group $R$ can change in such a way as to exploit some reso urce that the rest of $S$ cannot exploit, the situation improves for both $S$ and $R$. Here, $R$ prospers by specializing relative to $S$. This way of thinking about the environment does not construe environmental problems in a manner that is independent of organisms. Adaptation is not just a matter of "solving" a type of environment; it is rather a matter of finding a means of exploiting the environment in a way that is new relative to $S$. (For a related approach, see Lewontin 1982, 1983)

Consider diumal primates and diumal birds. On the second conception, they a re not just adapting to diuma lity; rather each is adapting its predecessor's lifestyle to a diumal environment. This means that as they evolved, each was starting from a different point, competing against organisms of their own quite different kinds, and adapting to inter-organism relations within quite different populations. Thus, each evolved diumal vision in the face of very different problems of adaptation. On the second conception, therefore, the fact that the visual systems of both birds and primates are adapted to a diumal environment does not imply that they will be the same. This is a history-bound way of thinking of visual specia lization. 
There is good reason to think that the specia lization-as-differentiation view is a better way to think about visual function. Consider colour vision. The ancestral mammalian colour vision system is ill adapted to searching for fruits among foliage, "because it has poor spatial resolution, and the fruits eaten by primates, when seen at a distance, are usually too small to be resolved by this subsystem" (Regan et al. 2001: 241). The ideal colour vision system for the task would make the fruit "pop out" against the background; that is, it would minimize the search time for such fruit, and make it relatively invariant rela tive to the number of green leafy distractors. This enables a monkey surveying the arboreal sc ene from afar quickly to detect where its chosen fruit are, rather than having to inspect each tree close up. What is needed, then, is that the primate sensitivity to the chromatic difference between these fruit and the leaves be maximized, while the difference among the leaves themselves should be minimized. It tums out that the peak sensitivities of primate colour receptive cones are indeed well spaced with regard to differentiating the red and orange of fruits from the green of leaves.

Notice then that the emergence of colour vision in primates is not a consequence of some general advantage that colour vision provides. It emerges for the specific purpose of detecting high-frequency red-green variation - variation of red and green in a "dappled and brindled" scene. It is signific ant that humans who are colour blind, even profoundly so, can get by quite well with brightness information alone - they can even detect colour, given certain conditions. What they unable to see is fine pattems in colour (cf. Mollon 2000). This function of the primate colour vision system - by Mollon's evidence, the most prominent added function - is thus specific to its historical origins, and the structural and morphological features of the system reflect these origins. To expla in these features demands that we look at the historical context in which specialized functions emerge. This is why homology thinking is appropriate here.

It is my thesis that adaptation is generally specialized in this manner - that the second view of adaptation outlined above is the correct one to take. The specializations described in this section are not merely adaptations to a broad type of environment; rather, they a re specific means of differentiation relative to predecessors. This is why homology thinking should prevail in functional taxonomy. The phenomenon of convergence is over-stated. 


\section{Broad Kinds of Vision}

The specialized functioning of visual systems in different kinds of organisms indic a tes that there are specific kinds of visual system, kinds that reflect origin. Avian vision is one kind; within it there may be even more specific kinds such as pigeon-vision, owl-vision, and eagle-vision. Mammalian vision is another kind, and it encompasses primate-vision, cat-vision, rodent-vision, and so on. The relationship between more inclusive and less inclusive kinds is that of ancestor and descendant. Mammalian vision is older than cat-vision, and it is more inclusive; cat-vision emerged by differentiation from a specific mammalian predecessor. This hierarchy does not contradict conventional wisdom about defining vision in tems of (proper) function. What is new in my suggestion is that the function emerges from historical circumstance. Homology thinking grounds functional thinking because history explains function, but not vice versa.

These considerations lead one to inquire about a broad kind of vision that includes both avian vision and mamma lia $n$ vision.

First, let us notice, there is no necessary conflict in the following propositions:

8. Avian vision and mammalian vision have defining functions in common. (This proposition is the foundation for functional definition.)

9. All defining functions should trace back to some common ancestor. (This is homology thinking. Love (this) issue argues that functions can be homologized and traced back to ancestors if 'function' is understood as activity or as causal role, rather than as selected effect.)

10. Birds and mammals differ with respect to many visual functions.

There is no conflict in these propositions for the trivial reason that even if visual animals diverge with respect to many functions, as (10) insists, there may still be shared functions available to define vision (asper [8]), and these functions may trace back to a common ancestor (as required by [9]). The question that I now want to consider is: Does homology thinking have a place here? 
There are two points to consider here. The first is that vertebrate visual systems seem to have a common ancestor. Further, they display certa in broad similarities. These start from their eyes, which are homologous in vertebrates. The eye-lenses focus a light-image on to a rrays of cells that transduce light into neural signals by means of certa in ancient proteins known as opsins. Vertebrate retinas are homologous, and the neural signals they transmit go through a homologue of the lateral geniculate nucleus to homologues of the primary visual cortex. This information seems to be passed on to a homologue of the extra-striate cortex for processing. (Until recently, it was not known that these parts of the cortex had homologues in birds and reptiles. See Medina and Reiner 2000). This evidence indic a tes that not only do vertebrate visual systems share functions, they also share certa in crucial parts and connections between them. Thus, they share a degree of functional organization. The difference between them is that these different parts are adapted to the extraction of different sorts of data from ambient light. The retinas of pigeons and dogs are homologous, but birds possess four kinds of cone cell and dogs only two. Similarly, the avian visual brain is adapted to different data-processing than those of the dog.

All of this vindicates the hierarchical picture that we have been developing. At the most abstract, most inclusive level we have shared functions of ancient origin located in certain shared parts of ancient origin. At lower levels of abstraction, we have more specific and more recent kinds of visual system in which the same parts with the same wining acquire new functions. (New parts may also have been added.) This supports a definition of the following sort:

11. Vertebrate vision is the ability to extract data from light by means of a data-processing system that receives input from eyes, and processes this input in structures homologous to the primary visual cortex and certain other brain structures found in all vertebrates.

This leads us to a second point. We might at this point try to unify all visual systems through homology. Here we might be encouraged by the fact that certa in homeobox genes, Emx-1, Emx-2, Tbr-1, and particularly Pax-6 have a role in the formation of visual systems not only in reptiles, birds, and mammals, but also in invertebrates. Is there then a homological account of all visual systems? No! This would be over-reaching, because though it is true that 
homologous genes control the formation of eyes etc. wherever they occur, it is not true that there is an eye that is the ancestor of both vertebrate and invertebrate eyes (Griffiths 2006; Love, this issue). The truth is rather that the homologous Pax- 6 and other such genes work in quite different ways in vertebrates and invertebrates to make non-homologous eyes (cf. Ereshefsky, this issue and Brigandt, this issue, on hierarchic al homology.) ${ }^{5}$

How then should we define the most inclusive kind of visual system - the kind that includes both vertebrate and invertebrate visual systems. Here, I suggest, we simply use a na logy thinking.

12. Vision is the a bility to extract da ta from light.

This broad definition is not devoid of explanatory value. We might use it to deduce certain general properties of visual systems - the occurrence of lenses, of photosensitive neurons, of certa in algorithms, and so on. Note, however, that (12) says nothing about parts or functional organization. (11), on the other hand, is committed to certain kinds of functional organization; it goes beyond selected effect functions to causal role functions (cf. Love, this issue).

\section{A Challenge to Homology Thinking: TVSS}

Is (11) a correct definition of vertebrate vision? Many think not. I now consider two challenges.

First, a challenge from Tactile Vision Sensory Substitution (TVSS). Paul Bach$y$-Rita and colleagues contend that "We see with the brain, not the eyes" (Bach-y-Rita et al. 2003: 285).

We developed tactile vision substitution systems (TVSS) to deliver visual information to the brain via arrays of stimulators in contact with the skin of one of several parts of the body (abdomen, back, thigh). Optical images picked up by a TV camera were transduced into a form of energy (vibratory or direct electrical stimulation) that could be mediated by the skin receptors. . . After sufficient training with the TVSS, our subjects reported experiencing the image in space, instead of on the skin. They leam to make perceptual judgments using visual means of analysis such as perspective, parallax, looming and zooming, and depth judgments... Although the

5 I am very much in debt to Ingo Brigandt and Paul Griffiths for helping me get straight on this matter. 
TVSS systems have only had between 100 and 1032 point arrays, the low resolution has been sufficient to perform complex perception and "eye"-hand coordination tasks. These have included facial recognition, accurate judgment of speed and direction of a rolling ball with over $95 \%$ accuracy in batting a ball as it rolls over a table edge, and complex inspection-assembly tasks. (286; empha sis added to mark important points)

These a re remarkable results. But is it right to say that TVSS provides humans with the kind of vision that the sighted among us enjoy? If so, the homologically correct definition (11) would seem to be mistaken, for it is clear that the system lacks homologically-defined eyes - the front-end of the TVSS system is not manufactured by a process initiated by the Pax- 6 gene.

Full discussion of this question would take us too far afield here. But I will outline two altemative responses that are in line with homology thinking. The second of these altematives seems to me the preferable one: it offers a reasonable response not only to TVSS itself, but to its inventors' take on what it does.

First, one could hold that though TVSS-adapted subjects are capable of sense-mediated access to visual qualities - i.e., qualities nomally sensed by the visual system - TVSS nonetheless fails to be a form of visual access to these qualities, either in the homology sense (11) applic able to vertebrates or humans, or even in the broad analogy sense (12). This is not, as it might seem, an uptight response to the phenomenon - merely a philosopher's quibble on the word 'visual'. For consider that there are all sorts of non-visual ways of gaining access to visual qualities. For example, one might be told a bout the visual qualities of some spectacle, and thus be able to visualize it. Or one might be conditioned to expect a certain visual stimulation. Suppose that one has experienced a certa in loud tone always being followed by a bright light. It might be that when one hears the loud tone blindfolded, one a mives at a visual image of the light accompanied by the belief that it has come on. Again, one has some sort of access to the light, but this access is not visual. And, one might say, it is not visual precisely because it is not mediated by the eye. This is one possible avenue of response to the TVSS phenomenon. One could say that it is one form of non-visual access to visual fea tures.

What makes this not an entirely satisfactory response is the significant similarities reported between Bach-y-Rita's TVSS-trained subjects and nomally 
sighted individuals - the fact that the former experience visual qualities "in space", which shows that the tactual experience has been significantly modified, and use "visual means of analysis such as perspective, parallax, looming and zooming, and depth judgments". We said at the beginning of this paper that homology thinking should be justified by explanatory success. Excluding TVSS as a form of vision leaves the use of visual means of analysis unexpla ined, and casts doubt on the utility of homology thinking in this a rea.

Here then is a second kind of response to the TVSS phenomenon. One might think that the evidence of non-tactual experience and visual means of analysis argues that though the entire visual system is not engaged by TVSS stimulation, parts of it are engaged. For perspective, parallax, and so on are not means of analysis that we are able to use voluntarily. They are not generalpurpose operations controlled by the perceiver, but are rather dedicated computational processes used in automated sub-personal visual processing. It appears therefore that TVSS stimulation somehow finds its way to and recruits automatic processes within the visual system, and that this is how TVSS-adapted subjects ga in access to visual qualities. Thus, though it is true that the eyes are not involved, some other parts of the visual system alluded to in (11) a re engaged in TVSS.

If this analysis is correct, then another kind of response to the TVSS challenge is possible. In definition (11) above, it seemed as if the input to the visual system had to come from the eyes. This approach is too strict; it rules out TVSS, which recruits parts of the visual system. But we need not take homology thinking in quite this way. There is a system in the brain that evolved in order to process data that it received from the eyes. It is possible that in some cases this system operates nomally even when it gets more or less isomorphic data from other sources. One might, in other words, read (11) as identifying a particular data-processing system in the brain, rather than requining that the data actually be provided by the eye. To make this explicit, we redefine vision as follows:

13. Vision is the ability to extract data from light by means of a dataprocessing system that evolved to process input received from the eyes.

This accommodates Bach-y-Rita's conclusion that "we see with the brain, not the eyes", within the constraints of homology thinking. 
Of course, we need not go all the way with Bach-y-Rita. We can make vision a comparative concept. Thus, we can distinguish various parts of the visual system: lens, retina, opsins, va rious data-processing systems. We can then say that something is fully a visual system if it makes use of all of these parts, and only approximates to a visual system if it performs visual functions, but without using all of them. This leads us in the direction of structural homologies in understanding the nature of vision. Considerations of space prevent me from pursuing this approach and its variants here. I simply note that it employs the part-by-part comparison that is one of the basic tools of homology thinking (cf. Ereshefsky, this issue). We are interested not just in the functioning of the entire visual system, but in how this functioning arises out of the inter-relationship of particular parts. One example of such a part is the primary visual cortex, Brodman's area 17 in humans. It is gemane to our understanding of vision that this bra in structure is homologous with a certain part of the avian Wulst.

\section{A Second Challenge: Prosthetic Vision}

This leads us to a more radical challenge. Bach-y-Rita's system involves the substitution of tactile receptors for the eyes, but with the involvement of other parts of the visual system. What if somebody were to develop an entirely optical-fibre and silic on-chip based prosthesis for the entire visual system from eyes on through to brain-based visual processing? Would an organism in which such a system was implanted possess vision? In homological terms, it would possess none of the parts of a visual system as conceived so far. Prosthetic vision satisfies (12) but not (13).

In my view the appropriate response to entirely prosthetic vision depends on how closely the prosthesis is modelled on biological vision. Suppose it was modelled on human vision functional bit by functional bit. Then, it would conform to the part-by-part a nalysis derived from homology thinking, and for this reason, it seems to me, it would be human vision. In such a system, the explanatory analysis of visual function would be preserved. Suppose, on the contrary, it was a substitute for vision that analysed light, but through a system quite different in structure from those that we find in the biological world. Suppose that it delivered the world by means of data-extraction from light in a way that enabled its possessor to navigate the extemal world, but in terms of features quite unlike those that biological organisms perceive visually. Then I 
would be less inclined to say that this is vision. My intuition would be: the more it copies biological vision, the more its functioning a rises out of the joint operation of functionally similar parts, the more it counts as vision - for the more it copies vision, the more it is subject to the explana tory stra tegies that vision scientists use.

What recommends such a point of view? Briefly, it is that our theoretical goal here is to account for vision in a way that adequately takes in how it actually operates. From a tra ditional perspective, there a re very few restric tions on a visual system. Any system that translated a lens-focused image into sensation would count. But once we acknowledge that visual systems do not simply convert a retinal image into picture-like visual sensation, we move to a characterization of visual system that rests on what data conceming the extemal world are extracted by a system. Specific types of visual system - the avian, the mammalian, and so on - are characterized in terms of their specific functioning. To fall under one of these types, a system should conform to their functional organization. A system that did not at least mimic actual biological visual functions would not provide anything like visual experience as we or other organisms know it. Of course, a system that did not mimic biological orga nization would still fall under (12) and thus it would count as a visual system. To this extent at least, the intuition of functionalists such as Neander can be preserved. True: but the novelty of the hierarchical conception inherent in homology thinking should be noted as an advance overpure analogy thinking.

I am proposing, then, that both vertebrate visual systems and systems copied from their functional parts and organization should count within the broad kind vertebrate vision. A notion like this could be accommodated by Ruth Millikan's (1984, chapter 1 ) notion of a reproductively established family. The nub of this idea is simply to broaden the notion of origins so that copying is included a longside biologic al evolution. Thus:

14. Vision is the ability to extract data by means of a data-processing system that either evolved to process input received from eyes, or was built to mimic the functions and sub-functions of such a system.

It should be noted that both (13) and (14) are intended to allow for systems that depart from perfect fidelity to the noms of an evolved system. Such systems would be less good than one that achieved perfect fidelity, but it would be a visual system nonetheless. 


\section{Function and Homology}

I'll conclude with a glance at what might be considered a novel aspect of my approach.

Nomally, the functional approach to understanding organic systems is considered antithetical to homology thinking - it is thought that if one defines kind s of visual system by what they have been selected to do and how they are organized to do it - that is, by either selected effect or causal role function - one will end up co-classifying things that do not have a common origin (cf. Gray 1991; G riffiths 1994; Amundson and Lauder 1994; Love, this issue). For it is thought possible that things with separate origins might do the same thing in the same way. For example, it is said, the wings of insects and of birds perform the same function, but since they are non-homologous, they a re different parts of different struc tures, and classifying them together will not get at their deepest features.

Along these lines, it is sometimes thought that if one demarcates cognitive kinds homologically, one will end up opposing functional understandings of these kinds. The approach that I take in this paper is not in agreement with this general assumption. In fact, the launch point of my argument in support of homology thinking is precisely the observation that visual functions correspond very closely to and are explained by common origins. It is one of the central theses of this paper that if biologic al systems in different types of orga nism have the same function, then, very likely, it is because they have the same origin. Thus, my reason for thinking about visual systems in homological terms is precisely that I think that one ought to think about cognitive functions themselves in homologic al tems.

Elsewhere, I have argued (Matthen 1998, 2000) that functional considerations are trumped by homology considerations in certa in cases, e.g., when thinking about emotions such as fear and anger or parts of the body such as bones. Bones cannot be defined functionally, because particular bones (e.g., the pelvis) perform different functions in different animals. Similarly, for the emotions: an emotion such as anger may function in different ways in different a nimals. For instance, the endocrinologic al aspects of anger may remain more or less the same in species where the social role that the emotion plays is very different from that of human anger. Thus, angercannot be defined in terms of its presumed function and cognitive structure in humans. Of course, there are 
other similarities a vailable to serve as definitions of these items - bones can be defined in terms of their place in a body plan, emotions by their endocrinal substrates. My claim is that homology thinking shows why these particular characteristics are the correct ones to use - bones change their shape and function; emotions change their role, but they are the same item because they are of common origin.

Bones in a single taxonomic class do not have the same function; emotions ditto. But visual systems that fall into the same class do have the same function, so I want to claim. The reason why function is so stable in vision is, I suggest, that vision is a complex system. In such systems, homology thinking operates at several different levels.

First, when we look at very broad classes of visual system that possess a common origin, we identify common parts: eyes, receptor cells, processing centres in the brain, etc. This identific ation of these parts proceeds straightforwardly by common origin.

Now, understanding visual functioning is obviously not just a matter of enumerating the parts of the visual system. It is an essential part of the explanatory task with regard to such complex systems is to show what these parts do, and how they work together to realize the system's characteristic activity (cf. Cummins 1983).

At this point, a more fine-grained level of homology thinking enters into the picture. As we shall see, the same partscan do different things in different visual systems. But here too origins are important because these differentiating specialized functions also trace back to common origins. Specialized functioning, however, traces back to more recent origins.

The scheme that I offer for homology thinking about vertebrate vision is thus hierarchical. The overall goal of the enterprise is to understand how the system is put together, and how the functioning of the parts contributes to the functioning of the whole. Homology thinking informs this enterprise at a variety of levels. The system's components are identified by relatively ancient origin, and, in many cases, the assembly of these parts as well. However, the same part may play different roles in different kinds of organism. This is expla ined by 
more recent origins. Thus, I argue for what Alan Love (this issue) calls homologies of function - function that traces back to common origin (see section IV). 
Amundson, Ron and Lauder, George (1994) Function without Purpose: The Uses of Causal Role Function in Evolutionary Biology. Biology and Philosophy 9: 443-469.

Avian Brain Nomenclature Consortium (2005) Avian Brains and a New Understanding of Vertebrate Brain Evolution. Nature Reviews Neuroscience 3: 151-159.

Bach-y-Rita, P., Tyler, M.E., and Kaczmarek, K. A. (2003) Seeing with the Brain. International Journal of Human-Computer Interaction 15: 285-295.

Cummins, Robert (1983) The Nature of Psychological Explanation Cambridge MA: Bradford Books, MITPress.

Darwin, Charles (1965) The Expression of Emotion in Man and Animals Chicago: University of Chic a go Press.

Delius, J uan D.; Emmerton, J a cky; Hörster, Wolfgang; Jäger, Ralph; a nd O stheim, Joachim (2000) Picture Recognition in Pigeons. In J. Fagot (ed.) Picture Perception in Animals Hove England: Psychology Press:1-35.

Dominy, N. J. and Lucas, P. W. (2001) Ecological Importance of Trichromatic Vision in Primates. Nature 410: 363-66.

Ereshefsky, Marc (2001) The Poverty of the Linnaean Hierarchy: A Philosophical Study of Biological Taxonomy Cambridge England: Cambridge University Press.

Gray, R. A. (1991) Behaviour, Brain and Phylogeny: Cladistic Analyses of Behavioural, Morphological and Molecular Data. International Journal of Neuroscience 57: 296.

Griffiths, Paul E.

(1994) Cladistic Classification and Functional Explanation. Philosophy of Science 61: 206-227.

(1997) What Emotions Really Are: The Problem of Psychological Categories Chic ago: University of Chic ago Press. 
(2006) Function, Homology, and Character Individuation. Philosophy of Science 73: 1-25.

(2007) Evo-Devo Meets the Mind: Towards a Developmental Evolutionary Psychology. In R. Sansom and R. Brandon (eds.), Integrating Evolution and Development: From Theory to Practice Cambridge, MA: MITPress:196-226.

Lewontin, Richard C.

(1980) Adaptation. The Encyclopedia Einaudi Milan: Eunaudi; Translated in Richard Lewins and Richard Lewontin (1985) The Dialectical Biologist Cambridge MA, Harvard UP.

(1982) Organism \& environment. In H. Plotkin (Ed.), Learning, Development, Culture New York: J ohn Wiley: 151-170.

(1983) Gene, organism \& environment. In D. S. Bendall (Ed.), Evolution: From Molecules to Man Cambridge: Cambridge University Press: 273-285.

Matthen, Mohan

(1998) Biological Universa Is and the Nature of Fear. Journal of Philosophy 95: 105-132.

(2000) "What is a Hand? What is a Mind?" Revue Internationale de Philosophie 214:653-672.

(2005) Seeing, Doing, and Knowing: A Philosophical Theory of Sense Perception Oxford: Clarendon Press.

Medina, Loreta and Reiner, Anton (2000) Do Birds Possess Homologues of Mammalian Primary Visual, Somatosensory and Motor Cortices? Trends in Neurosciences 23: 1-12.

Millikan, Ruth G. (1984) Language, Thought, and Other Biological Categories Cambridge MA: Bradford Books, MITPress.

Mollon, J. D. (2000) 'Chemies Among the Leaves': The Evolutionary Origins of Color Vision. In S. Davis (ed.) Color Perception: Philosophical, Psychological, Artistic, and Computational Perspectives New York: Oxford University Press: 10-30. 
(1991) Functions as Selected Effects: The Conceptual Analyst's Defence. Philosophy of Science 58: 168-184.

(2002) Types of Traits: The Importance of Functional Homologues. In A. Ariew, R. Cummins, and M. Perlman (eds.) Functions: New Essays in the Philosophy of Psychology and Biology Oxford: Oxford University Press: 390415.

Preuss, Todd (2004) What Is It Like to Be a Human? In M. Gazzaniga (ed.) Cognitive Neurosciences 3rd Edition (Cambridge MA: Bradford Books, MIT Press): 5-22.

Regan, B. C., Julliot, C., Simmen, B., Viénot, F., Charles-Dominique, P., and Mollon, J. D. (2001) Fruits, foliage and the evolution of colour vision. Philosophical Transactions of the Royal Society of London B 356: 229-83.

Sober, Elliott (1988) Reconstructing the Past: Parsimony, Evolution, and Inference Cambridge MA: Bradford Books, MITPress.

Sumidge, Alison K., Osorio, Daniel, and Mundy, Nicholas I. (2003) Evolution and Selection of Trichromatic Vision in Primates. Trends in Ecology and Evolution 18: 198-205.

Tjønneland, A., Økland, S., and Nyland, A (1987) Evolutionary Aspects of the Arthropod Heart. Zoologica Scripta 16: 167-175. 